\title{
Assessment of High-Velocity Free Surface Flow Interaction with a Bridge Pier in A Curved Channel
}

\author{
Ahmed H. Mahmoud and Amir M. Mobasher \\ Civil Engineering Department, Faculty of Engineering, Al-Azhar University, Cairo, Egypt \\ Correspondence Author: \\ Amir M. Mobasher, Civil Engineering Department, Faculty of Engineering, Al-Azhar University, Cairo, Egypt \\ E-mail: dr_amir_mobasher@yahoo.com
}

Received date: 12 January 2019, Accepted date: 20 February 2019, Online date: 28 March 2019

Copyright: (c) 2019 Ahmed H. Mahmoud and Amir M. Mobasher This is an open-access article distributed under the terms of the Creative Commons Attribution License, which permits unrestricted use, distribution, and reproduction in any medium, provided the original author and source are credited.

\begin{abstract}
Free surface flow in the vicinity of bridge piers on a fixed channel bed is a classical problem of open-channel hydraulics. Prior prediction of flow profiles can inform and improve the design of expensive structures, such as high velocity channels and bridges, in particular the height of channel walls and bridge decks. This study used experimental work to simulate free surface flow through a curved rectangular cross section channel containing a single bridge pier. The study investigates the impact of curvature degree of the channel, variations of contraction ratio, discharge (represented by a Froude number), and the length and thickness and shape of the bridge pier on the high velocity free surface flow profile. A simulation of flow in the curved channel with the obstruction was performed for different inflow discharges determining the supercritical flow in the cross-section of a channel constriction. The corresponding afflux (maximum backwater rise in upstream due to bridge constrictions) were measured for each discharge and the measurements yield detailed information about flow structure near the obstruction. The results demonstrated that the values of afflux for the supercritical flow at the curved channel are bigger than those of straight channel, and the difference between the afflux values in both curved and straight channels depends on the curvature degree of the channel.
\end{abstract}

Keywords: Free surface flow, Afflux, Backwater rise, Bridge piers, curved channel.

\section{INTRODUCTION}

The constructed bridges across the waterways may have long spans and are supported on piers. Piers are integral parts of a bridge structure that obstructs the natural river flow causing an increase in water surface elevation due to bridge constrictions, particularly during flood events, which frequently cause significant increases in river discharge and other high-velocity channels.

The high-velocity channel is a control flood channel which was designed to discharge water as fast as possible to discharge points such as a river or sea. This kind of channels is usually constructed at a sufficient slope so that the flow is supercritical, thus reducing the flow area and concentration time.

Apart from (local) scour around the piers and bridge abutments and possible bed erosion, there is a considerable backwater effect of the bridge. The maximum increase in water level above the normal unobstructed level due to the constriction is known as afflux (maximum backwater) and seen in Fig. 1. The increasing in afflux is related to the type of flow (subcritical or supercritical) and the increase in the degree of obstruction. The establishment of afflux levels is crucial for the design of upstream dykes and other protective works and also for the location of safe bridge deck levels (to avoid the flooding of the deck and any consequent structural damage). It is equally important to determine the minimum precise length of span (economic considerations) which will not cause undesirable afflux levels (Novak et al., 2007).

The flow between piers may be subcritical or supercritical. The following analysis is very helpful to distinguish between sub-or-supercritical states in between piers. The energy equation for the reach between the contracted section 2 and section 3 below the contraction (assuming hydrostatic pressure distribution with a negligible bed slope) (Fig. 1 ) is,

$$
\varepsilon\left[y_{2}+\frac{V_{2}^{2}}{2 g}\right]=\left[y_{3}+\frac{V_{3}^{2}}{2 g}\right]
$$

or,

$$
\varepsilon \cdot y_{2}\left[2+F_{r_{2}}^{2}\right]=y_{3}\left[2+F_{r 3}^{2}\right]
$$




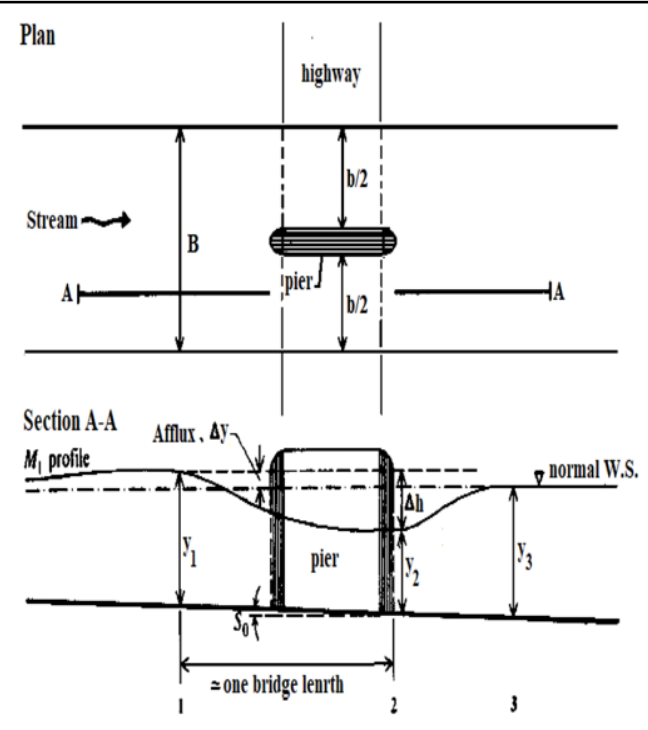

Fig. 1: Flow between bridge piers.

Where $\mathrm{F}_{\mathrm{r} 2}$ and $\mathrm{F}_{\mathrm{r} 3}$ are the Froud numbers at sections 2 and 3, $\mathrm{F}_{\mathrm{r} 2}=\mathrm{V}_{2} / \mathrm{Vgy}_{2}, \mathrm{~F}_{\mathrm{r} 3}=\mathrm{V}_{3} / \mathrm{Vgy}_{3}$, where $\mathrm{V}_{2}, \mathrm{~V}_{3}$ are flow velocity at sections 2 and 3 , respectively, and $\mathrm{y}_{2}, \mathrm{y}_{3}$ are flow depths at sections 2 and 3, respectively, and $\varepsilon$ represents the percentage of energy recovery, since energy loss will occur between sections. By the continuity of flow (Soliman, 1989),

$$
\begin{aligned}
& \mathrm{V}_{2} \mathrm{by}_{2}=\mathrm{V}_{3} \mathrm{~B} \mathrm{y}_{3} \\
& \mathrm{~F}_{\mathrm{r} 2}{ }^{2} \sigma^{2} \mathrm{y}_{2}{ }^{2}=\mathrm{Fr}_{\mathrm{r} 3}{ }^{2} \mathrm{y}_{3}{ }^{2}
\end{aligned}
$$

Where $\sigma$ is called the contraction ratio $=$ flow width at constriction section "b"/ flow width of the cross-section without constriction "B". Eliminating $\mathrm{y}_{2}$ and $\mathrm{y}_{3}$ from Eqs. 2 and 4,

$$
\sigma^{2}=\frac{\varepsilon^{3} F_{r 3}^{2}\left[2+F_{r_{2}}^{2}\right]^{3}}{F_{r_{2}}^{2}\left[2+F_{r 3}^{2}\right]^{3}}
$$

When the flow at section 2 is critical, $F_{r 2}=1$. The value of $F_{r 3}$ that satisfies this condition is called the limiting value and is designated by $F_{r 3 L}$. Thus for $\mathrm{F}_{\mathrm{r} 2}=1$, the above equation becomes,

$$
\sigma^{2}=\frac{27 \varepsilon^{3}\left[F_{r_{3 L}}\right]^{2}}{\left.2+F_{r_{3 L}}\right]^{2}}
$$

For a given $\sigma$, therefore, the flow through the obstruction is critical if $\mathrm{Fr}_{3}=\mathrm{F}_{\mathrm{r} 3 \mathrm{~L}}$. Examination of Eq. 5 indicates that flow through the obstruction is subcritical if $\mathrm{F}_{\mathrm{r} 3}<\mathrm{F}_{\mathrm{r} 3 \mathrm{~L}}$ and supercritical if $\mathrm{F}_{\mathrm{r} 3}>\mathrm{F}_{\mathrm{r} 3 \mathrm{~L}}$.

Under the subcritical flow condition, the velocity distribution across the spaces between piers is nonuniform. For this reason, it would have been a reasonable approach if a momentum equation were applied between sections 1 and 3 (Fig. 1) such that $\left(\mathrm{M}_{1}-\mathrm{M}_{3}=\mathrm{F}\right)$, where $\mathrm{M}_{1}$ and $\mathrm{M}_{3}$ are the momentum at sections 1 and 3 , respectively and $\mathrm{F}$ is the drag force on piers. However, the estimation of $\mathrm{F}$, if piers are considered as flat plates, can never be exact because the pier nose and tail must have a role in the problem.

Yarnell (Yarnell, 1934) obtained experimental results for different types of piers, which are expressed in the following empirical equation:

$$
\frac{\Delta y}{y_{3}}=K \cdot F_{r_{3}}^{2}\left(K+5 F_{r_{3}}^{2}-0.60\right) \cdot\left(\alpha+15 \alpha^{4}\right)
$$

\begin{tabular}{|c|c|c|}
\hline Pier shape & $\mathbf{K}$ & Remarks \\
\hline Semicircular nose and tail & 0.90 & \multirow{3}{*}{$\begin{array}{l}\text { All values applicable for piers with length to breadth ratio equal } \\
\text { to } 4 \text {; conservative estimates of } \Delta y \text { have been found for larger } \\
\text { ratios. }\end{array}$} \\
\hline Lens-shaped nose and tail & 0.90 & \\
\hline Twin-cylinder piers with connecting diaphragm & 0.95 & \\
\hline Twin-cylinder piers without diaphragm & 1.05 & \multirow{3}{*}{$\begin{array}{l}\text { The lens-shaped nose is formed from two circular curves, each } \\
\text { of radius to twice the pier width and each tangential to a pier } \\
\text { face. }\end{array}$} \\
\hline $90^{\circ}$ triangular nose and tail & 1.05 & \\
\hline Square nose and tail & 1.25 & \\
\hline
\end{tabular}

Where $\alpha=1-\sigma$ and $\mathrm{K}$ is the coefficient reflecting the pier shape, table 1 gives values of $\mathrm{K}$ to be substituted in Eq. 7 .

Table 1: Values of "K" as a function of pier shape (Yarnell, 1934). 
The high-velocity curved channels of interest in this work have a high discharges and so the velocity is high enough to achieve $F_{r 3}>F_{r 3 L}$, and thus the flow is supercritical. The chart in Fig. 2 gives a graphical solution for supercritical flow through bridge piers. With the proper value of $\sigma$, determine the limiting value $\mathrm{F}_{\mathrm{r} 3 \mathrm{~L}}$ from Eq. 6. Then enter $\mathrm{F}_{\mathrm{r} 3} / \mathrm{F}_{\mathrm{r} 3 \mathrm{~L}}$ on the chart and read $\Delta \mathrm{y} / \mathrm{y}_{3}$ for the given pier shape. This value multiplied by $\mathrm{y}_{3}$ gives the backwater $\Delta y$.

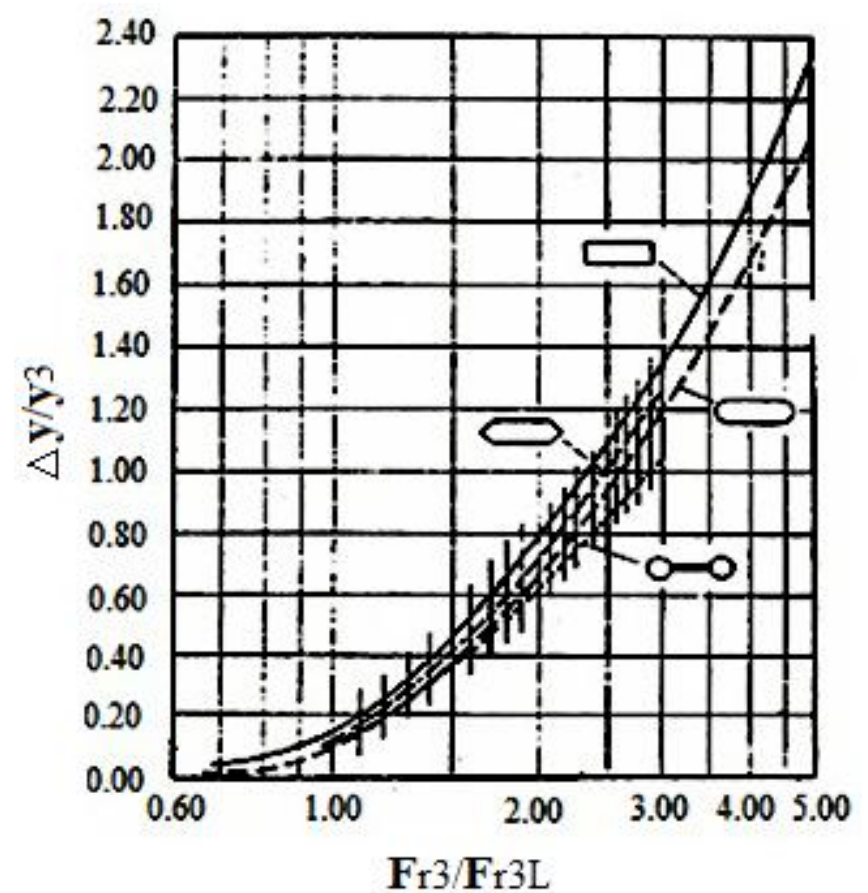

Fig. 2: Chart for determining afflux of supercritical flow through bridge piers (Soliman, 1982).

More researchers have a try to improve analytical, semi-experimental or experimental equations for free surface flow interaction with a bridge pier in straight channels. As illustrated by Henderson (Henderson, 1966) and (Sturm, 2001), the survey of afflux may be caused to flow retraction due to bridges piers was being by Yarnell (Yarnell, 1934). Moreover, the afflux upstream bridges was studied by Atabay et al. (Atabay et al., 2018) Beffa (Beffa, 1996), Charbeneau et al. (Charbeneau and Holly, 2001; El-Alfy, 2006; El-Alfy, 2009;Hunt and Brunner, 1995; Kaatz, 1997;Seckin, 2004; Smibabu et al., 2011; Soliman, 1989).

This research was initiated to study the afflux due to bridge piers in curved channels, experimentally for supercritical flow condition, which is the type of flow that exists in rivers and other high-velocity channels during flood events. The empirical finding on afflux at different pier shapes position of among departments in a 30 degree curved channel is presented. To understand the effect of the curvature on the afflux, the finding is dissimilarity between with those in a straight channel. The data of the afflux may be caused to constriction of the flow by bridge piers presented in this study paper are utilize in the evaluation of a new formula, which could be applied in calculate afflux at supercritical flows among bridge piers in curved channels.

\section{DIMENSIONAL ANALYSIS}

The relationships between all parameters, affecting the afflux, were comprehended. According to the dimensional analysis technique of Buckingham $\pi$-Theorem, a relation between the effective parameters and the afflux was deduced, where the methods of dimensional analysis are built upon the Fourier principle of dimensional homogeneity. This principle stated that any equation, expressing a relationship between physical quantities, must be dimensionally homogenous All parameter and geometry are defined in Fig. 3. 


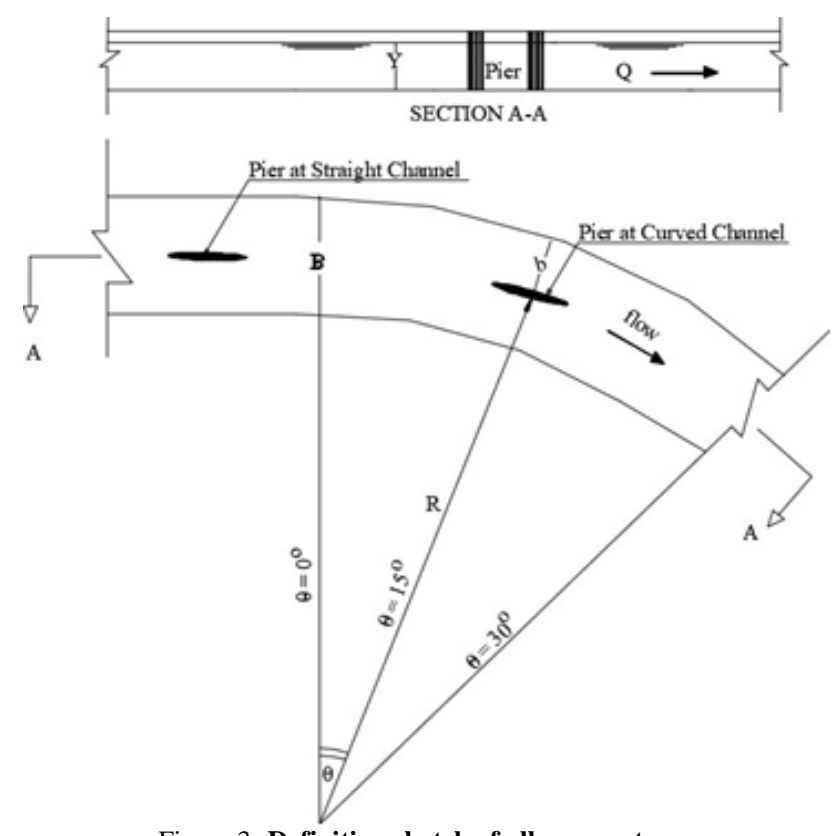

Figure 3: Definition sketch of all parameters.

Functional relationships are obtained between the relative depths of the afflux $\Delta y$ for all parameter.

In this study: the afflux $\Delta \mathrm{y}$ is the dependent variable. It can be expressed as a function of all other independent variables as follows:

$$
\Delta \mathrm{y}=\phi(\mathrm{B}, \mathrm{R}, \mathrm{b}, \mathrm{t}, \mathrm{L}, \mathrm{y}, \mathrm{K}, \Theta, \mathrm{Q}, \rho, \mathrm{g}, \mu,)
$$

where, $\mathrm{B}$ is the channel width, $\mathrm{R}$ is the radius of channel, $\mathrm{b}$ is the amount of space between two things from pier to channel side, $t$ is the thickness of the pier in the centre, $\mathrm{L}$ is the length of the pier, $\mathrm{y}$ is the normal water depth, $\mathrm{K}$ is the coefficient reflecting the pier shape, $\Theta$ is the degree of the curved channel, $\mathrm{Q}$ is the discharge, $\rho$ is the density of fluid, $g$ is the gravity acceleration, and $\mu$ is the dynamic viscosity.

Using Buckingham's $\pi$-Theorem, nine variables and two repeated changes were obtained. These changes can be easily coordinated in the following non -dimensional $\pi$-terms.

$\pi_{1}=\Delta \mathrm{y} / \mathrm{y}, \pi_{2}=\mathrm{B} / \mathrm{y}, \pi_{3}=\mathrm{b} / \mathrm{y}, \pi_{4}=\mathrm{t} / \mathrm{y}, \pi_{5}=\mathrm{L} / \mathrm{y}, \pi_{6}=\mathrm{R} / \mathrm{B}, \pi_{7}=\mathrm{K}, \pi_{8}=\Theta, \pi 9=\mathrm{Q}^{2} / \mathrm{B}^{5} \mathrm{~g}$ According to Buckingham $\pi$-Theorem, the general form of

relationship between these variables is written as follows:

$$
\phi=\left(\frac{\Delta y}{y}, \frac{B}{y}, \frac{b}{y}, \frac{t}{y}, \frac{L}{y}, \frac{R}{y}, \frac{Q^{2}}{g B^{5}}, K, \theta\right)=0
$$

Taking the properties of $\pi$-terms into account, the following relationship was obtained:

$$
\phi_{1}=\left(\frac{\Delta y}{y}, \frac{b}{B}, \frac{L}{t}, \frac{R}{t}, F r, K, \theta\right)=0
$$

Finally, the following function was established:

$$
\frac{\Delta y}{y}=\phi_{1}\left(\frac{b}{B}, \frac{R}{t}, \frac{L}{t}, F r, K, \theta\right)
$$

\section{EXPERIMENTAL WORK}

The experimental investigation has been conducted in a new innovative re-circulating channel of $800 \mathrm{~cm}$ long and rectangular cross-section steel frame of $60 \times 30 \mathrm{~cm}^{2}$ with visible bright polycarbonate sides to allow visual observation of the water surface. The experimental model so as the implemented devices are presented in Fig. 4, where some shots to the channel are provided.

The channel encompasses three parts, the first and last parts are $3 \mathrm{~m}$ long while the third part is the curved middle part with an angle of $30^{\circ}$ in the horizontal direction. A sharp-crested triangular weir at the downstream of the return channel was used to measure the discharge. Water was supplied from a sump into the entrance basin., The water level in the channel, was controlled by a tailgate situated at the end of channel. 


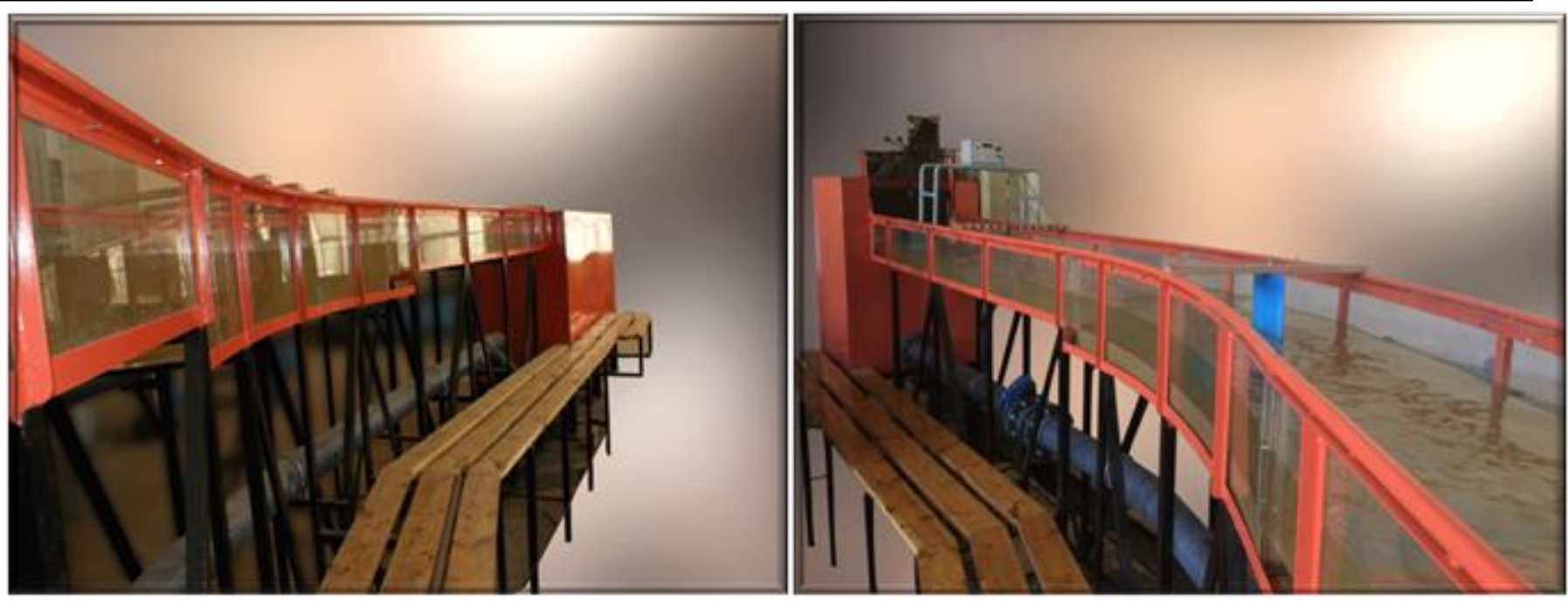

Fig. 4: Shots for the experimental channel.

In the present work 144 models are investigated to cover the various aspects for the problem under consideration. A thoroughly designed experimental program is carried out to investigate these models. Experiments were conducted under clear-water conditions at four different water discharges 55.83, 60.49, 70.68 and $81.91 \mathrm{lit} / \mathrm{sec}$ and the Froude number was ranged between 1.10 and 1.38, just downstream. The depth of flow in all the experiments was constant and equal to $13 \mathrm{~cm}$.

The pier models of different shapes for different contraction ratios $0.93,0.95$ and 0.97 are made using wood, and three pier length /pier width ratios $(\mathrm{L} / \mathrm{t})$ were tested (i.e. 5, 6.67 and 10). The shapes are rectangular, triangular (angle of slope $=60^{\circ}$ ) and semi-circular nose and tail. The pier was located in section 0 15 and 30 degrees from the beginning of the curved channel and also in the middle of the upstream straight channel separately.

The flow depths were measured by using a point gauge allowing measurements accuracy of $\pm 0.1 \mathrm{~mm}$, and velocity was measured locally at various points (i.e. at different depths along with the water depth). For tracing the velocity distribution at any sections, a mini flow meter, with outer diameter $7.0 \mathrm{~mm}$, was used to find the velocity in the horizontal direction $(\mathrm{Hz})$ in $\mathrm{cm} / \mathrm{sec}$ based on a calibration curve for this apparatus, as indicated photos.

The following parameters were measured for each run; upstream flow depth $\left(\mathrm{y}_{1}\right)$, approach velocity $\left(\mathrm{V}_{1}\right)$, flow depth through vents $\left(\mathrm{y}_{2}\right)$, flow velocity through vents $\left(\mathrm{V}_{2}\right)$, downstream flow depth $\left(\mathrm{y}_{3}\right)$; and downstream flow velocity $\left(\mathrm{V}_{3}\right)$. Sample of experiments is illustrated through Fig. 5.

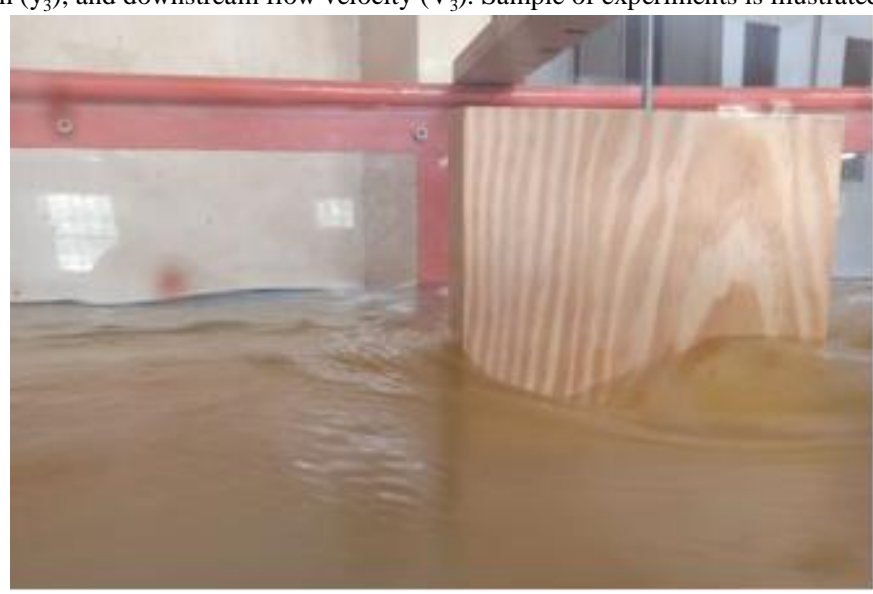

Fig. 5: Photos for afflux under supercritical flow condition between piers.

\section{ANALYSIS OF DATA AND INTERPRETATION OF RESULTS}

After reviewing the literature, adopting a theoretical approach, executing the experiments and undertaking measurements so as recording readings together with documenting observations so as capturing photos, it was due to analyze all the results, plot them on graphs, list them in tables present them and discuss them. For the 144 models, results of the afflux upstream the pier situated at various sections of the channel down different flow conditions with different pier shapes are presented here. In this study effect of the increase in Froud number $\left(\mathrm{F}_{\mathrm{r}}\right)$ resulted from the growing of flow discharge $(\mathrm{Q})$ on the afflux is investigated. The downstream flow parameters $\left(\mathrm{y}_{3}, \mathrm{~V}_{3}\right)$ are used in computing the value of Froude number $\left(\mathrm{F}_{\mathrm{r} 3}\right)$. The downstream Froude number $\left(\mathrm{F}_{\mathrm{r} 3 \mathrm{~L}}\right)$ conformable to critical flow conditions between piers for each worth of contraction ratio $(\sigma)$ is calculated from Eq. 7 be controlled on each run information. If the value of $\mathrm{Fr}_{3}$ is greater than the value of $\mathrm{F}_{\mathrm{r} 3 \mathrm{~L}}$, the flow between piers is supercritical. The dimensionless afflux $\left(\Delta \mathrm{y} / \mathrm{y}_{3}\right)$ may be caused to supercritical flow between bridge piers is observed through Figs. 6 to 15.

\section{Impact of the channel curvature angle on The afflux}

Figs. 6, 7 and 8 represent the relationship between dimensionless afflux $\left(\Delta y / y_{3}\right)$ and $\mathrm{F}_{\mathrm{r} 3} / \mathrm{Fr}_{3 \mathrm{~L}}$ for different pier Locations under supercritical condition. For flow between rectangular end-noses piers, triangular end-noses piers and semicircular end-noses piers, respectively. From these Figs. It could be noticed that the proportional afflux is immediately equivalent to the relative value of downstream Froude number $\left(\mathrm{F}_{\mathrm{r} 3}\right)$ and the afflux $\Delta \mathrm{y}$ decrease as the pier is located further downstream in the curved channel (i.e. increasing $\Theta$ decreases $\Delta y$ ). At all discharges, the maximum afflux occurs for pier at section 0 degree of the curved channel $\left(\Theta=0^{\circ}\right)$ and the minimum afflux occurs for pier at section 30 degree of the curved channel $\left(\Theta=30^{\circ}\right)$. It is clear also from these Figs., values of afflux at the curved channel is more significant than those of straight channel. The increase in the afflux values due to the curvature in the channel reached to $39.89 \%, 22.38 \%$ and $12.61 \%$ for $\Theta=0^{\circ}, 15^{\circ}, 30^{\circ}$, respectively, compared to the corresponding afflux values in the straight parts of the channel. With greater in the quantity of flow, variation between the straight channel and curved channel sections begin to be additional significant. 


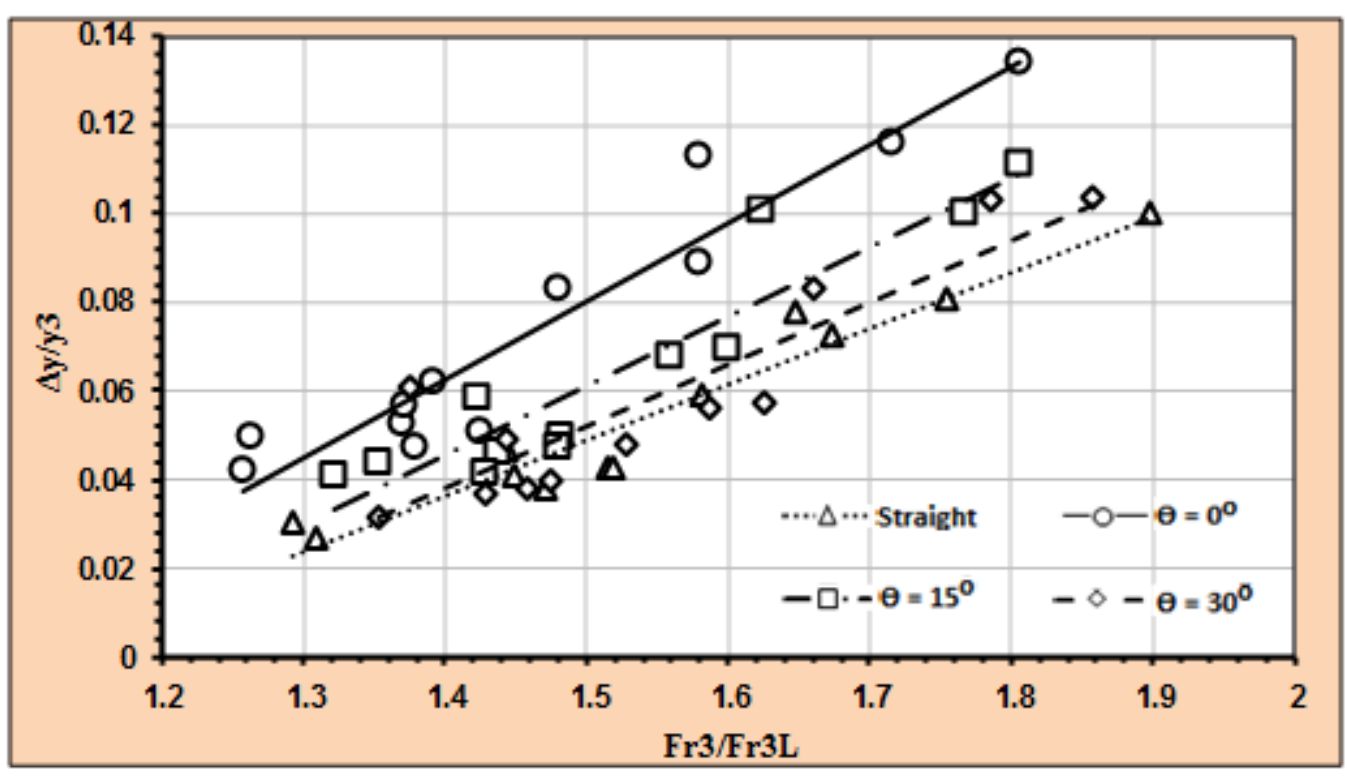

Fig. 6: Relationship between dimensionless afflux $\left(\Delta y / y_{3}\right)$ and $F_{r 3} / F_{r 3 L}$ for flow between rectangular end-noses piers with different pier locations under supercritical condition.

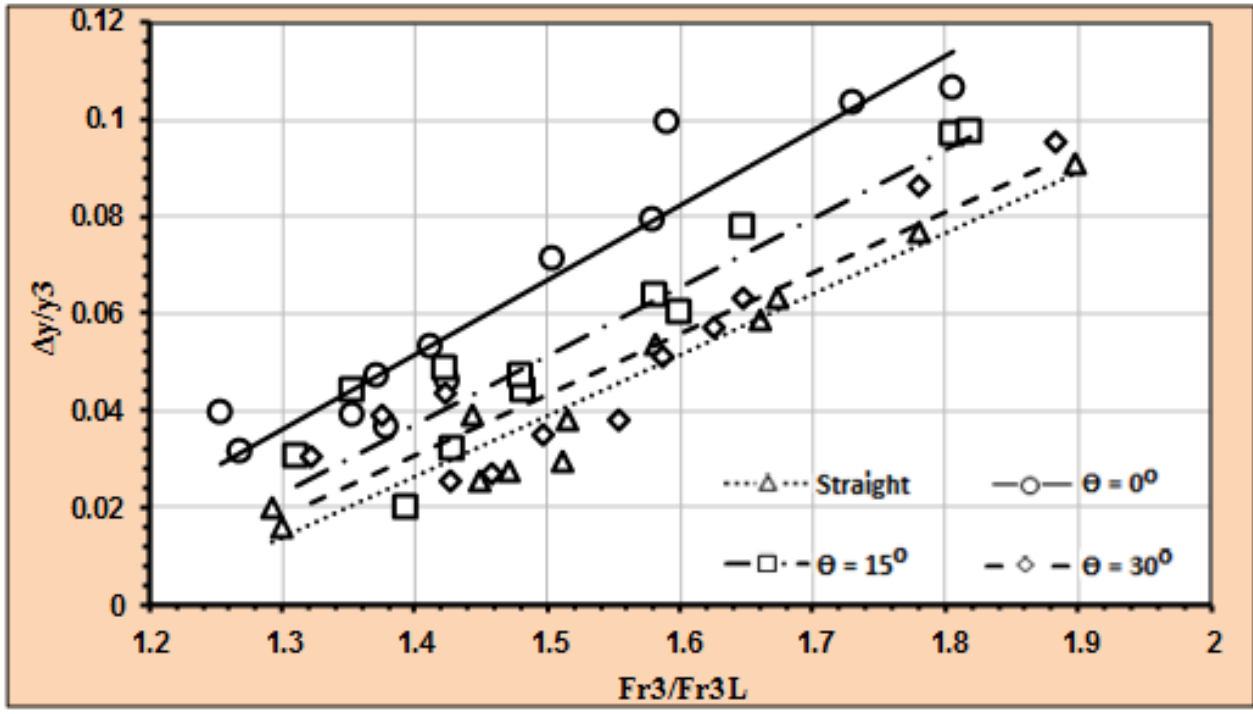

Fig. 7: Relationship between dimensionless afflux $\left(\Delta y / y_{3}\right)$ and $F_{r 3} / F_{r 3 L}$ for flow between triangular end-noses piers with different pier locations under supercritical condition.

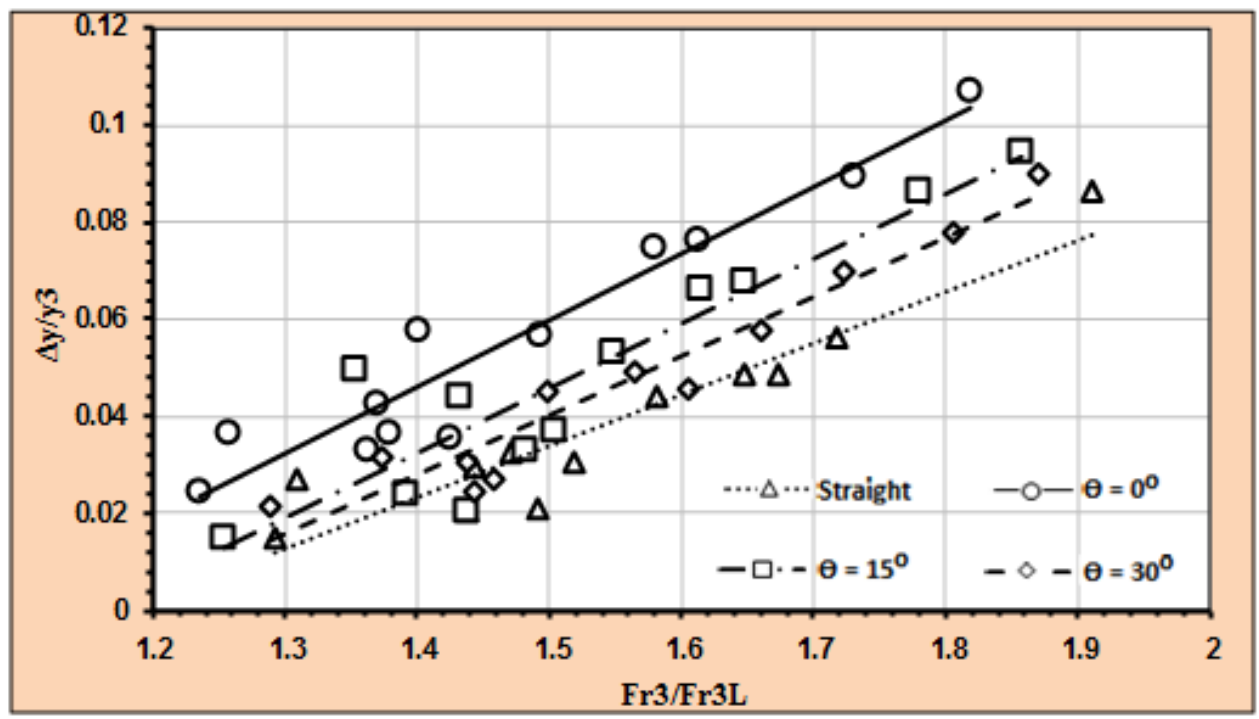


Citation: Ahmed H. Mahmoud and Amir M. Mobasher, Assessment of High Velocity Free Surface Flow Interaction with A Bridge Pier in a Curved Channel Journal of Applied Sciences Research. 15(1): 1-11. DOI: 10.22587/jasr.2019.15.1.1

Fig. 8: Relationship between dimensionless afflux $\left(\Delta y / y_{3}\right)$ and $F_{r 3} / F_{r 3 L}$ for flow between semicircular end-noses piers with different pier locations under supercritical condition.

\section{Compare among The experimental and The calculated Values}

Figs. 9, 10, 11 and 12 represent a compare among the experimental and the studied values of the dimensionless afflux $\left(\Delta \mathrm{y} / \mathrm{y}_{3}\right)$ and $\mathrm{F}_{\mathrm{r} 3} / \mathrm{Fr}_{3 \mathrm{~L}}$ under the supercritical condition at the straight channel and sections 0,15 and 30 degrees of the curved channel $\left(\Theta=0^{\circ}, 15^{\circ}, 30^{\circ}\right)$.

As it is evident from these Figs, for all different pier locations, the trend of the experimental values of dimensionless afflux upstream piers $\left(\Delta y / y_{3}\right)$ is approximately similar to the trend of the corresponding predicted ones according to Yarnell (Yarnell, 1934) at supercritical flow between piers. The comparatively great variation for the three geometrical shapes of piers with supercritical flow could be mention to the truth that Yarnell's chart (Fig. 2) was obtained for a pier length to pier width equal to 4:1 (Yarnell, 1934), while the pier length to pier width ratio in this study ranges among 5:1 to 10:1.

Using the experimental data, this yielded the derived linear relations to calculate afflux at supercritical flow situation between bridge piers with different pier locations depending on downstream flow properties at the bridge site.

$$
\begin{aligned}
& \frac{\Delta y}{y_{3}}=0.1199 \frac{F r_{3}}{F r_{3 L}}-0.1391 \quad \text { For straight channel } \\
& \frac{\Delta y}{y_{3}}=0.1549 \frac{F r_{3}}{F r_{3 L}}-0 . \underline{1634} \quad \text { For curved channel }\left(\Theta=0^{\circ}\right) \\
& \frac{\Delta y}{y_{3}}=0.1426 \frac{F r_{3}}{F r_{3 L}}-0.1611 \quad \text { For curved channel }\left(\Theta=15^{\circ}\right) \\
& \frac{\Delta y}{y_{3}}=0.1275 \frac{F r_{3}}{F r_{3 L}}-0.1460 \quad \text { For curved channel }\left(\Theta=30^{\circ}\right)
\end{aligned}
$$

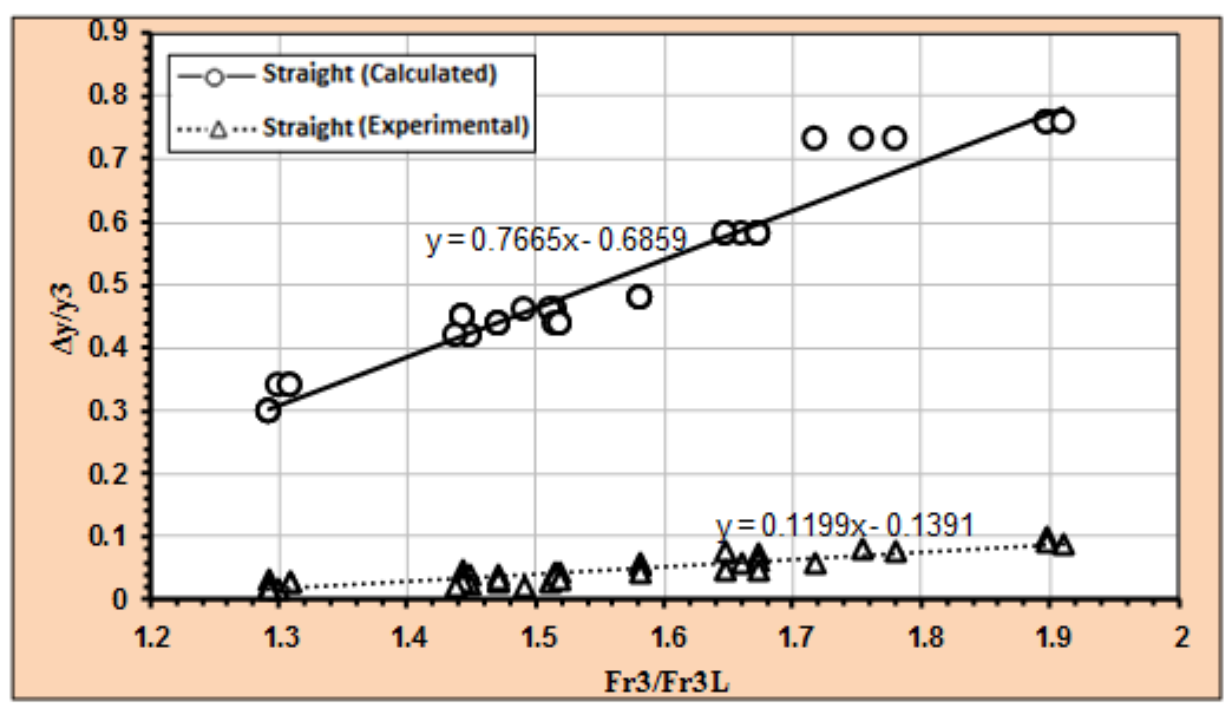

Fig. 9: Relationship between dimensionless afflux $\left(\Delta y / y_{3}\right)$ and $F_{r 3} / F_{r 3 L}$ under supercritical condition for straight channel.

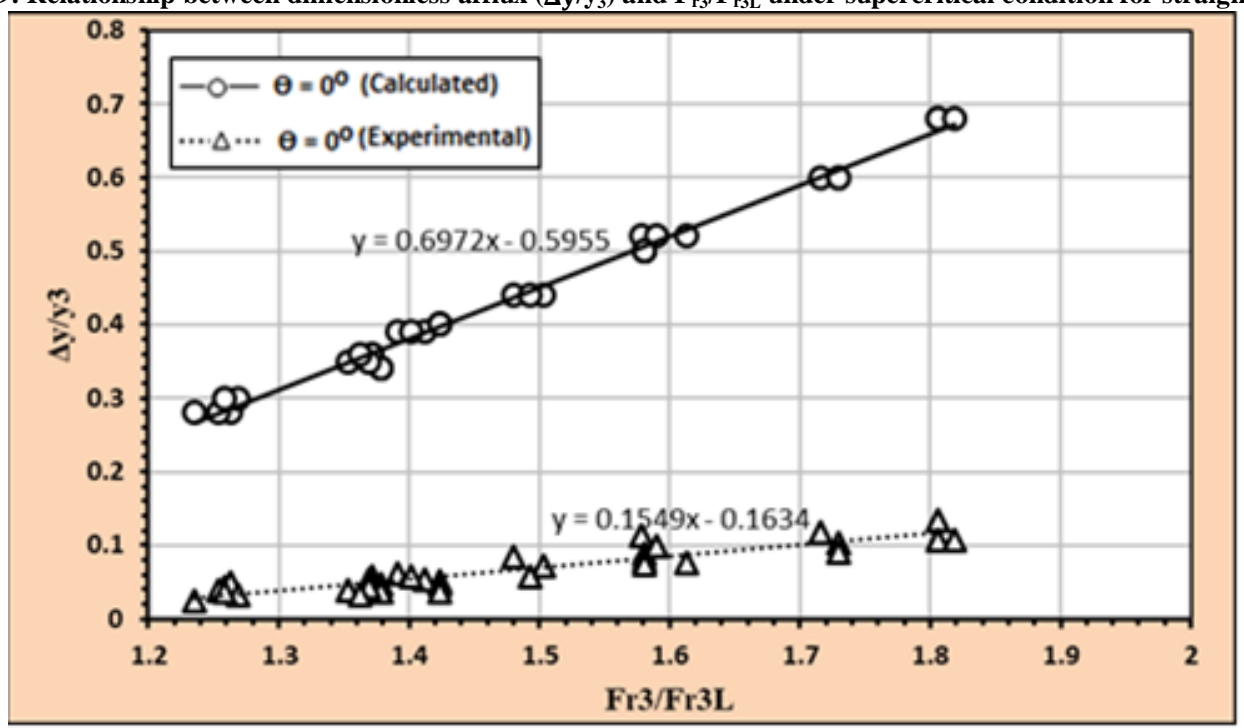

Fig. 10: Relationship between dimensionless afflux $\left(\Delta y / y_{3}\right)$ and $F_{r 3} / F_{r 3 L}$ under the supercritical condition at section 0 degree of the curvature $\left(\theta=0^{\circ}\right)$. 


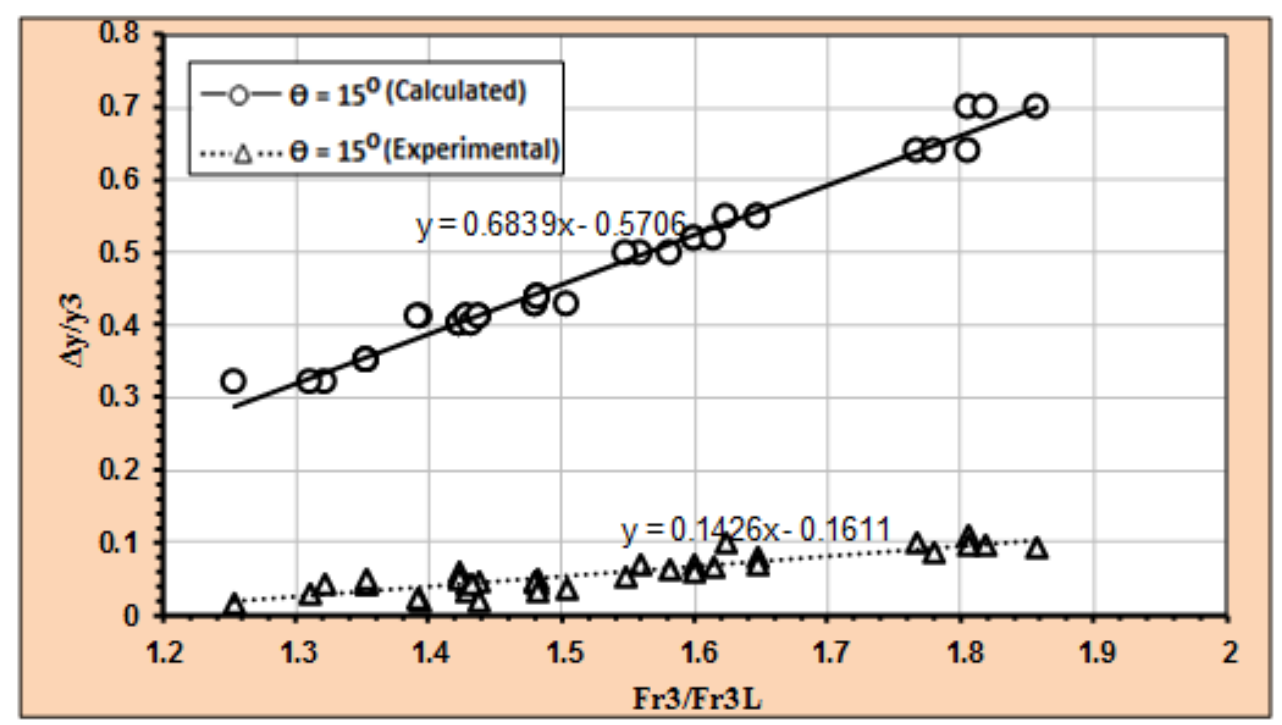

Fig. 11: Relationship between dimensionless afflux $\left(\Delta y / y_{3}\right)$ and $F_{r 3} / F_{r 3 L}$ under the supercritical condition at section 15 degree of the curvature $\left(\Theta=15^{\circ}\right)$.

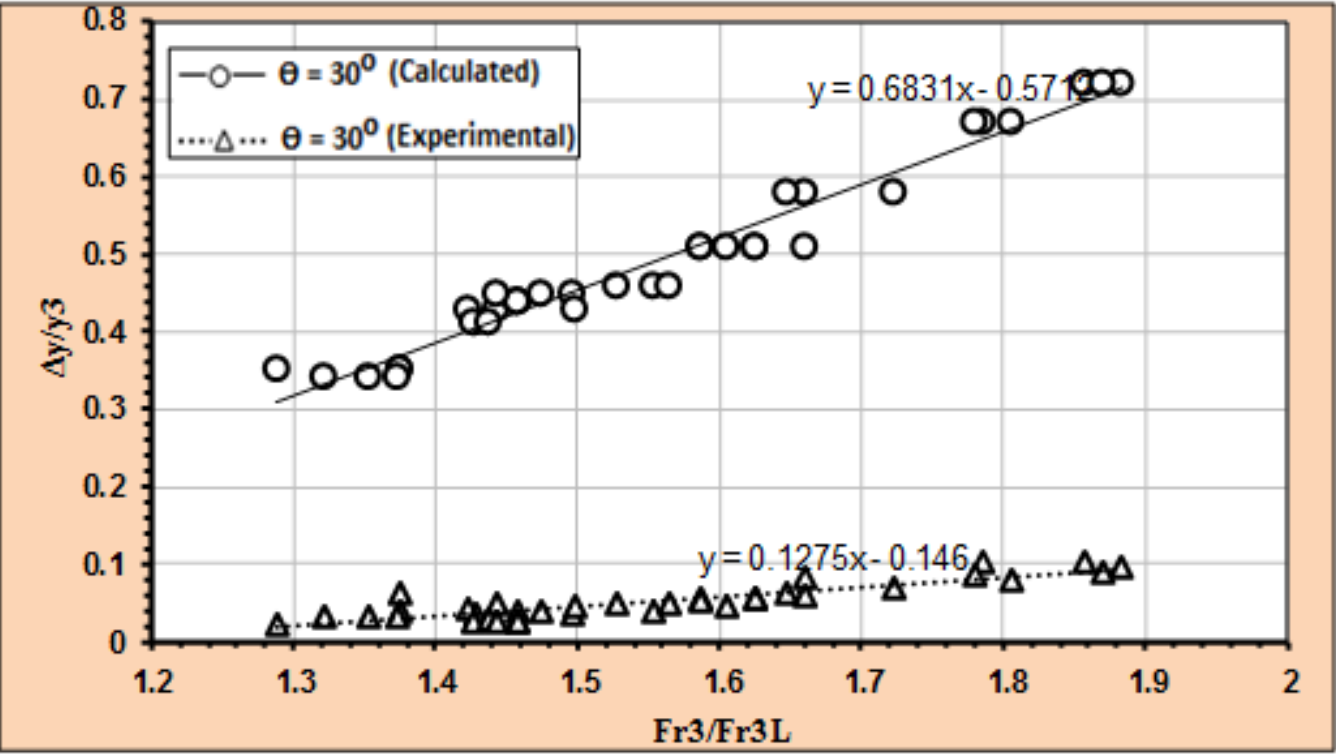

Fig. 12: Relationship between dimensionless afflux $\left(\Delta y / y_{3}\right)$ and $F_{r 3} / F_{r 3 L}$ under the supercritical condition at section 30 degree of the curvature $\left(\Theta=30^{\circ}\right)$.

\section{Impact of Pier Shape on The afflux}

The influence of the geometrical shape of pier end-nose on upstream afflux at supercritical flow condition between piers is also clarified in Figs. 6 to 12. From these Figs., it is found that the afflux upstream triangular end-noses piers follows the identical trend as in rectangular piers for all pier locations in the curved channel and also for the straight channel, but the values of afflux in the issue of the triangular end-noses pier are less than those for rectangular ones for the identical flow conditions. The afflux for the semicircular end-noses pier is smaller than those for both triangular and rectangular end-noses piers, respectively. The reduction in afflux for both semicircular and triangular end-noses piers could be a reference to their influence in redirecting flow velocities, which decreased the afflux. This is certainly by the studies carried out by Yarnell (Yarnell, 1934).

\section{Impact of Contraction Ratio on The afflux}

Figs. 13, 14 and 15 represent the relationship between dimensionless afflux $\left(\Delta y / y_{3}\right)$ and $F_{r_{3}} / \mathrm{Fr}_{3 L}$ with different pier locations under the supercritical condition for contraction ratios $0.97,95$ and 93 , respectively. From Figs., for all different pier locations, the afflux may be caused to piers constriction at supercritical flow between piers is adversely proportional to the contraction ratio $\sigma$ for different pier flow conditions. These Figs. show that the afflux is directly proportional to $\mathrm{F}_{\mathrm{r} 3} / \mathrm{Fr}_{3 \mathrm{~L}}$ at among values of contraction rate. This could be mention to the increase in flow quantity occurred from the increasing of $\mathrm{F}_{\mathrm{r} 3}$, in which the amount of $\mathrm{F}_{\mathrm{r} 3 \mathrm{~L}}$ is fixed for each value of contraction ratio as clarified in Eq. 6 . The excess of flow rate between piers performed in increasing of the afflux upstream the bridge site, which is certain from the chart in Fig. 2, in which the afflux be controlled fundamentally on the value of $\mathrm{F}_{\mathrm{r} 3}$. 


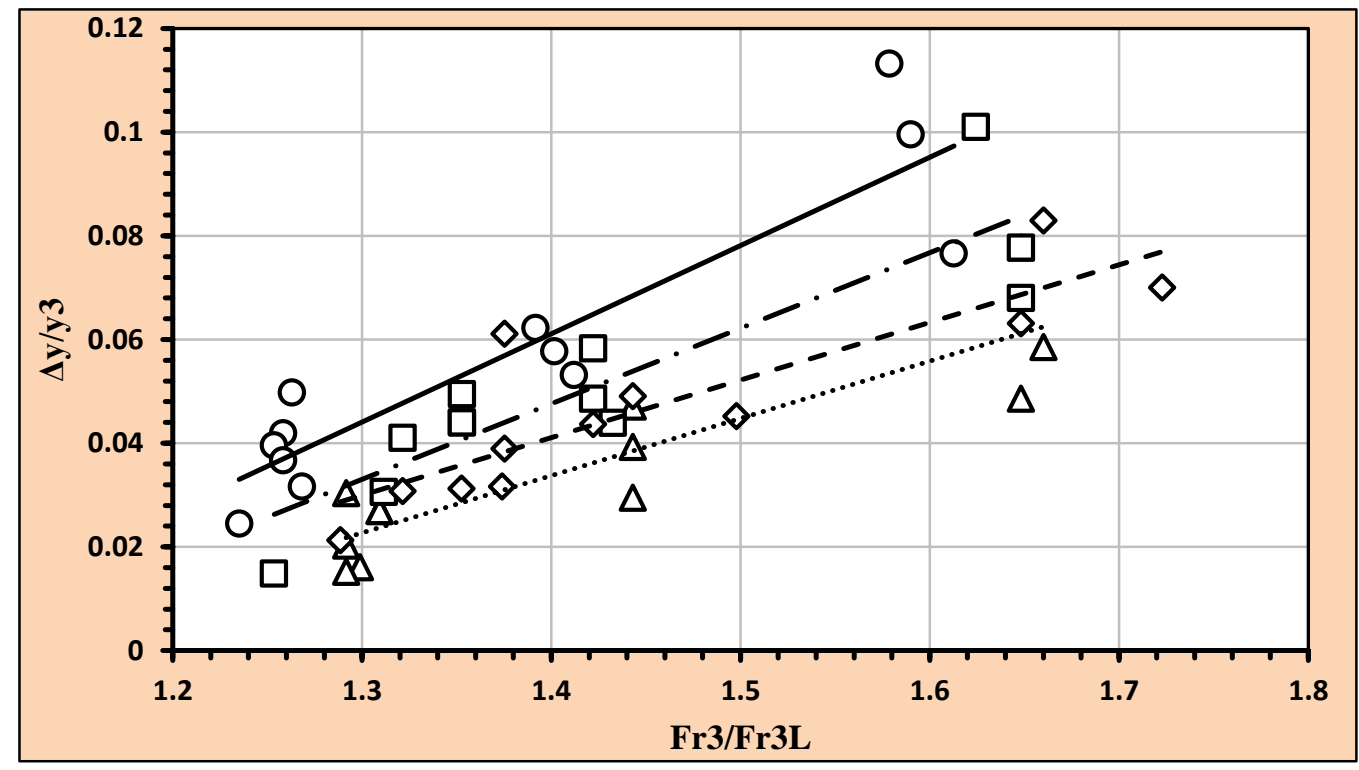

Fig. 13: Relationship between dimensionless afflux $\left(\Delta y / y_{3}\right)$ and $F_{r 3} / F_{r 3 L}$ for contraction ratio 0.97 with different pier locations under supercritical condition.

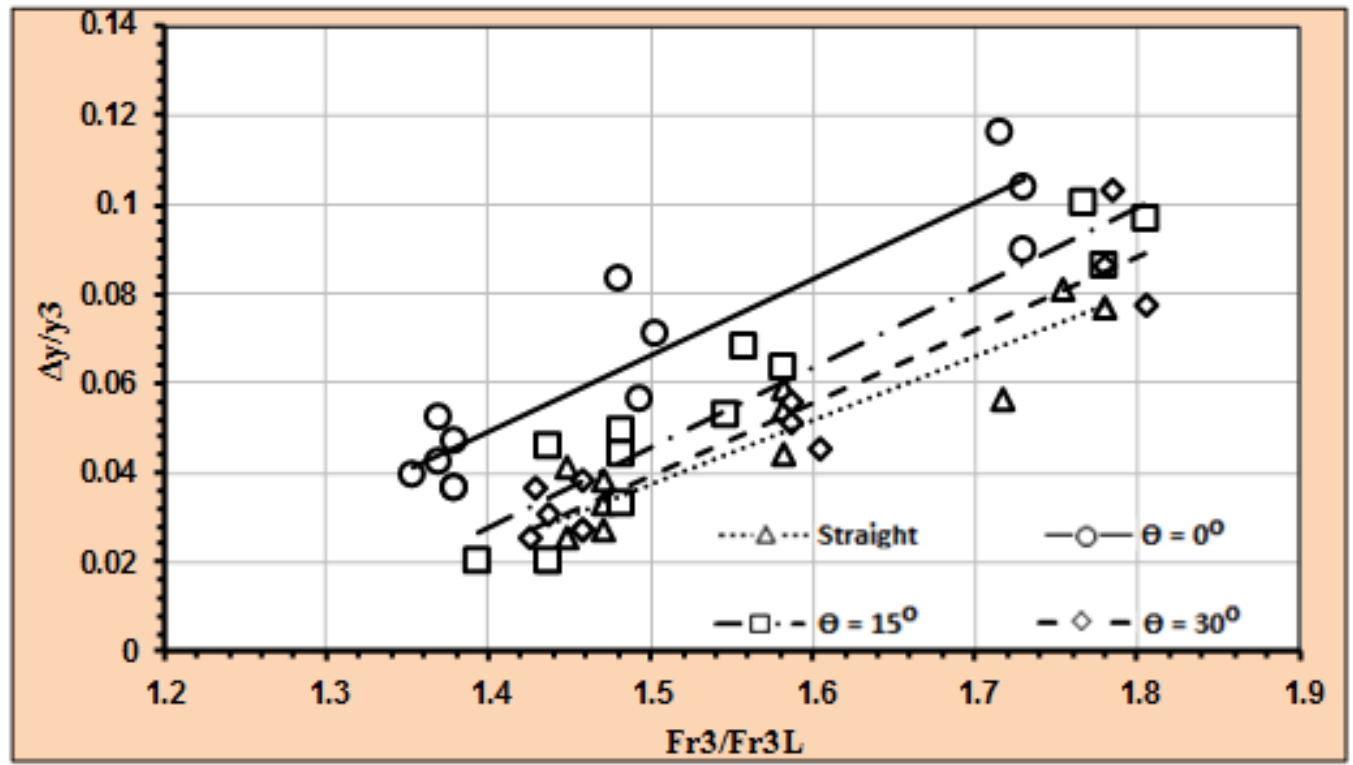


Fig. 14: Relationship between dimensionless afflux $\left(\Delta y / y_{3}\right)$ and $F_{r 3} / F_{r 3 L}$ for contraction ratio 0.95 with different pier locations under supercritical condition.

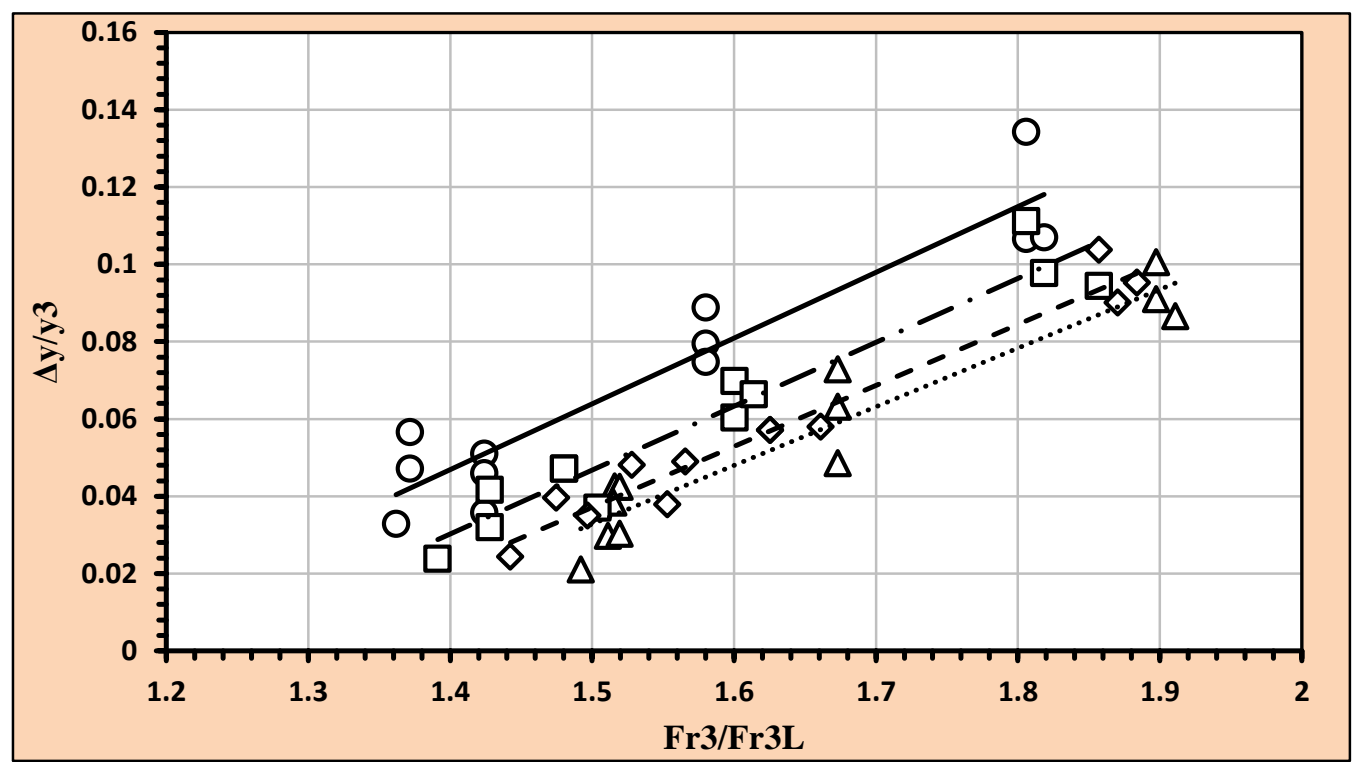

Fig. 15: Relationship between dimensionless afflux $\left(\Delta y / y_{3}\right)$ and $F_{r 3} / F_{r 3 L}$ for contraction ratio 0.93 with different pier locations under supercritical condition.

\section{CONCLUSION}

From the above mentioned investigation phases, some conclusions were deduced around the possibility of the implementation of the piers in the curved part in the high-velocity channels, also the best shapes and angles of curvature in the channel to reduce the effect of afflux upstream piers. The deduced conclusions are summarized, as follows:

1 Values of afflux at the curved channel are more significant than those of the straight channel. The increase in the afflux values due to the curvature in the channel reached to $39.89 \%, 22.38 \%$ and $12.61 \%$ for $\Theta=0^{\circ}, 15^{\circ}, 30^{\circ}$, respectively, compared to the corresponding afflux values in the straight parts of the channel. With increasing in the quantity of flow, variation among straight channel and curved channel sections begin to be additional significant.

2 The afflux decreases as the pier are located further downstream in the curved channel. At all discharges, the maximum afflux occurs for pier at section 0 degree of the curved channel $\left(\Theta=0^{\circ}\right)$ and the minimum afflux occurs for pier at section 30 degree of the curved channel $\left(\Theta=30^{\circ}\right)$.

3 The following relationships were advanced for prophecy the afflux may be caused to flow contraction by bridge piers at the supercritical continuous situation between bridge piers:

$$
\begin{array}{ll}
\frac{\Delta y}{y_{3}}=0.1199 \frac{F r_{3}}{F r_{3 L}}-0.1391 & \text { For straight channel } \\
\frac{\Delta y}{y_{3}}=0.1549 \frac{F r_{3}}{F r_{3 L}}-0.1634 & \text { For curved channel }(\Theta=0) \\
\frac{\Delta y}{y_{3}}=0.1426 \frac{F r_{3}}{F r_{3 L}}-0.1611 & \text { For curved channel }(\Theta=15) \\
\frac{\Delta y}{y_{3}}=0.1275 \frac{F r_{3}}{F r_{3 L}}-0.1460 & \text { For curved channel }(\Theta=30)
\end{array}
$$

4 In both curved and straight channels, the afflux for semicircular end-noses pier is less than those for both triangular and rectangular end-noses piers, respectively.

5 The afflux is immediately commensurate to the proportional value of downstream Froude number and also to aversely proportional to the value of contraction ratio.

6 The afflux upstream bridge piers for supercritical flow between piers is inversely commensurate to the value of contraction ratio.

\section{REFERENCES}

[1] Atabay, S., Assar, K. H. A., Hashemi, M., and Dib, M., " Prediction of the backwater level due to bridge constriction in waterways", Water and Environment Journal 32. Print ISSN 1747-6585, 2018.

[2] Beffa, C., "Backwater computation for transcritical river flows", Journal of Hydrau- lics Engineering, Vol. 122, No.12, 1996.

[3] Charbeneau, Randall J. and Holly, Edward R., "Backwater effects of bridge piers in subcritical flow", Center of Transportation Research, University of Texas, Project Summery Report 1805-S, 2001.

[4] Chow, Ven Te, "Open channel hydraulics", McGraw-Hill, Inc., 1959

[5] El-Alfy, K. S., " Experimental study of backwater rise due to bridge piers as flow obstructions ", Tenth International Water Technology Conference, Hurghada, Egypt IWTC 10, 2006.

[6] El-Alfy, K. S., " Backwater rise due to flow constriction by bridge piers", Thirteenth International Water Technology Conference, Hurghada, Egypt IWTC $13,2009$. 

Journal of Applied Sciences Research. 15(1): 1-11. DOI: 10.22587/jasr.2019.15.1.1

[7] Henderson, F. M., "Open channel flow”, Macmillan Publishing Co., Inc., New York, 1966.

[8] Hunt, John H. and Brunner, Gary W., "Flow transitions in bridge backwater analy- sis", US Army Crops of Engineering, Institute of Water Resources, 1995.

[9] Kaatz, Kelly, J., " Analysis of alternatives for computing backwater at bridges", Jour- nal of Hydraulics Engineering, Vol. 12, Issue 9, 1997.

[10] Novak, P., Moffat, A.I.B., Nalluri, C., and Narayanan, R., " Hydraulic Structures", ISBN10: 0-203-96463-2 e-book, Fourth edition published by Taylor \& Francis, 2007.

[11] Seckin, Galip, "A simple formula for estimating backwater at bridge constriction", Can. J. Civ. Engrg., Vol. 31 (4), 2004.

[12] Smibabu, C. R., Sabansh, R. M., Narasimhan, R., and Chandhni, A. R., " Backwater rise and drag characteristics of bridge biers under sub-critical flow conditions", Eu- ropean Water 36: 27-35, 2011.

[13] Soliman, M.A., "Design of irrigation structures and works", Al-Azhar University, Cairo, Egypt, 1989.

[14] Sturm, Terry W, "Open channel hydraulics" McGraw-Hill Inc., New York, 2001.

[15] Yarnell, D.L., "Bridge piers as channel obstructions", U. S. Department of Agricul- ture, Tech. Bull. No. 442, November 1934. 